\title{
Principais bactérias encontradas em uroculturas de pacientes com Infecções do Trato Urinário (ITU) e seu perfil de resistência frente aos antimicrobianos
}

\author{
Main bacteria found in urine cultures of patients with urinary tract infections (UTI) and their \\ resistance profile to antimicrobials \\ Principales bacterias encontradas en urocultivos de pacientes con infecciones del tracto urinario
}

(ITU) y su perfil de resistencia a los antimicrobianos

Recebido: 16/05/2021 | Revisado: 27/05/2021 | Aceito: 30/05/2021 | Publicado: 13/06/2021

\author{
Mariane Silva Oliveira \\ ORCID: https://orcid.org/0000-0001-5616-4213 \\ Universidade Federal do Piauí, Brasil \\ E-mail: mary-anny12@hotmail.com \\ Gabriela do Nascimento Caldas Trindade \\ ORCID: https://orcid.org/0000-0001-8748-7365 \\ Universidade Federal do Piauí, Brasil \\ E-mail: gabrielacaldas.gc@gmail.com \\ Keyla Liana Bezerra Machado \\ ORCID: https://orcid.org/0000-0003-3689-8994 \\ Universidade Federal do Piauí, Brasil \\ E-mail: lilibezerra2@hotmail.com \\ Maria do Carmo Machado Santos \\ ORCID: https://orcid.org/0000-0001-9648-780X \\ Universidade Federal do Piauí, Brasil \\ E-mail: carminhamachado17@gmail.com \\ Evaldo Hipólito de Oliveira \\ ORCID: https://orcid.org/0000-0003-4180-012X \\ Universidade Federal do Piauí, Brasil \\ E-mail: evaldohipolito@gmail.com
}

\begin{abstract}
Resumo
Este trabalho teve por objetivo de avaliar a prevalência das principais bactérias encontradas em uroculturas causadoras de ITU em pacientes atendidos em hospitais dos diferentes estados brasileiros, bem como o perfil de resistência e sensibilidade bacteriana a antimicrobianos, por meio da busca em um banco de dados atualizados, promovendo uma revisão do tema proposto. Para realização desse estudo de revisão literária, foi feito uma busca de artigos recentes (até 7 anos da publicação) nos bancos de dados de periódicos eletrônicos Pubmed, Medline, Lilacs e Scielo, com disponibilidade de textos completos para a coleta de dados que contenham as principais bactérias encontradas em uroculturas de pacientes com Infecções do Trato Urinário juntamente aos sua resistência frente aos mais diversos tipos de antibióticos. Incluiu-se artigos publicados entre os anos de 2014 a 2020 e que tratassem sobre as principais bactérias encontradas em uroculturas e seu perfil de resistência frente aos antimicrobianos. Tendo como critérios de exclusão, qualquer artigo que não trate de nenhum dos temas anteriormente citados e que tivessem sido publicados fora do tempo cronológico delimitado. Foram encontradas 4173 uroculturas positivas, sendo o micro-organismo mais frequentemente isolado a Escherichia coli, seguido de Klebsiella pneumoniae, e Proteus mirabilis. Foi possível constatar altos índices de resistência à $E$. coli para alguns antimicrobianos da primeira escolha para tratamento da ITU, como ampicilina $(55,32 \%)$ e sulfametoxazol+trimetroprim (34,36\%) Esses dados coletados através de uma base de dados atualizada demonstram a necessidade de promovem o conhecimento a cerca dessa infecção a fim de definir uma terapia empírica adequada, criando assim um esquema terapêutico que auxiliará os profissionais da saúde durante o tratamento dos pacientes com ITU.
\end{abstract}

Palavras-chave: Infecção urinária; Resistência bacteriana em uroculturas; Antimicrobianos.

\begin{abstract}
This study aimed to assess the prevalence of the main bacteria found in urocultures that cause UTI in patients seen in hospitals in different Brazilian states, as well as the profile of bacterial resistance and sensitivity to antimicrobials, by searching an updated database, promoting a review of the proposed theme. In order to carry out this study of literary review, a search for recent articles (up to 7 years after publication) was carried out in the databases of electronic periodical Pubmed, Medline, Lilacs e Scielo, with availability of complete texts for the collection of data containing the main bacteria found in the urocultures of patients with Urinary Tract Infections along with their resistance to the most
\end{abstract}


diverse types of antibiotics. Articles published between 2014 and 2020 that addressed the main bacteria found in urine cultures and their antimicrobial resistance profile were included. With exclusion criteria, any article that does not deal with any of the themes mentioned above and that has been published outside the defined chronological time. 4,173 positive urocultures were found with the microorganism most frequently isolated to Escherichia coli, followed by Klebsiella pneumoniae and Proteus mirabilis. It was possible to check high levels of resistance to E. coli for some antimicrobials of first choice for the treatment of UTI, such as ampicillin $(55.32 \%)$ and sulfamethoxazole + trimetroprim $(34.36 \%)$. These data collected through an updated database demonstrate the need to promote knowledge about this infection in order to define an appropriate empirical therapy, thus creating a therapeutic scheme that will assist health professionals during the treatment of patients with UTI.

Keywords: Urinary infection; Bacterial resistance in urocultures; Antimicrobials.

\section{Resumen}

Este estudio tuvo como objetivo evaluar la prevalencia de las principales bacterias encontradas en urocultivos que causan ITU en pacientes atendidos en hospitales de diferentes estados brasileños, así como el perfil de resistencia bacteriana y sensibilidad a antimicrobianos, mediante la búsqueda de una base de datos actualizada, promoviendo una revisión. del tema propuesto. Para la realización de este estudio de revisión literaria se realizó una búsqueda de artículos recientes (hasta 7 años después de su publicación) en las bases de datos de revistas electrónicas Pubmed, Medline, Lilacs e Scielo, con disponibilidad de textos completos para la recolección de datos que contengan las principales bacterias encontradas en urocultivos de pacientes con Infecciones del Tracto Urinario junto con su resistencia a los más diversos tipos de antibióticos. Se incluyeron artículos publicados entre 2014 y 2020 que abordaban las principales bacterias encontradas en los urocultivos y su perfil de resistencia a los antimicrobianos. Con criterio de exclusión, cualquier artículo que no aborde ninguno de los temas anteriormente mencionados y que haya sido publicado fuera del tiempo cronológico definido. Se encontraron 4173 urocultivos positivos, siendo el microorganismo aislado con mayor frecuencia a Escherichia coli, seguido de Klebsiella pneumoniae y Proteus mirabilis. Se pudo verificar altas tasas de resistencia a E. coli para algunos antimicrobianos de primera elección para el tratamiento de la ITU, como ampicilina $(55,32 \%)$ y sulfametoxazol + trimetroprim $(34,36 \%)$ Estos datos recogidos a través de una base de datos actualizada demuestran la Es necesario promover el conocimiento sobre esta infección para definir una terapia empírica adecuada, creando así un esquema terapéutico que ayude a los profesionales de la salud durante el tratamiento de los pacientes con ITU.

Palabras clave: Infección urinaria; Resistencia bacteriana em urocultivos; Antimicrobianos.

\section{Introdução}

\subsection{Sistema urinário e seus constituintes}

O sistema urinário é formado por dois rins, dois ureteres, uma bexiga e uma uretra, que compõe um conjunto de órgãos que atuam em prol do bom funcionamento do organismo. Esses constituintes têm a função de remover os produtos finais do metabolismo, além de regular os fluidos corporais. É por meio da filtração glomerular que o sistema urinário assume importante função de remover resíduos e minerais indesejáveis, promovendo a purificação do sangue. Essas substancias são eliminadas juntamente com o excesso de água do corpo, na forma de urina (Santos, A. M. et al., 2020).

Os rins têm como função, regular o volume e a composição do sangue e remover suas impurezas, além disso, excretam o excesso de hidrogênio, provocando efeito direto no controle do $\mathrm{pH}$ sanguíneo, esse processo resulta na formação da solução que vai ser excretada, denominada urina (Caneppa, 2017).

Correspondentes a dois tubos musculares oriundo dos rins, os ureteres transportam a urina recém formata até a bexiga urinária, e o transporte urinário nesses ductos de dá por contrações peristálticas das paredes musculares dos ureteres, porém, a pressão hidrostática e a força da gravidade também contribuem. A bexiga opera como um reservatório da urina, antes da sua eliminação para fora do corpo, essa eliminação se dá através da micção. No lugar em que os ureteres entram na bexiga, válvulas fisiológicas impedem o fluxo reverso da urina para os rins, esse mecanismo é o que ajuda a defender os rins das possíveis infecções do trato urinário inferior. Além da urina ter propriedades antimicrobianas, a ação do fluxo urinário durante a excreção da urina também tende a remover micro-organismos potencialmente infecciosos (Tortora, 2017).

A uretra é um pequeno tubo que se inicia no assoalho da bexiga e termina no exterior do corpo, esse tubo é a porção terminal do sistema urinário, e se difere demasiadamente em função e tamanho entre homens e mulheres. Nas mulheres ela é 
mais curta, com apenas $5 \mathrm{~cm}$ de comprimento e transporta exclusivamente urina para o meio externo, já nos homens o seu comprimento é maior, e além de transportar urina, funciona como um canal que conduz o sêmen para o exterior do corpo durante a ejaculação, porém nas mulheres os micro-organismos a atravessam com maior facilidade (Caneppa, 2017; Santos, F. A. et al., 2019).

Na bexiga existem colônias de micro-organismos em pequena quantidade, mas na Infecção do Trato Urinário (ITU) ocorre um quadro infeccioso devido a invasão bacteriana e uma propagação atingindo desde a uretra até os rins. Geralmente essas bactérias migram para a bexiga de forma ascendente de restos fecais ou da microbiota vaginal ou perianal (Corrêa, 2018).

O bom funcionamento do sistema urinário, é crucial para que a manutenção dos processos de excreção e homeostase do corpo humano ocorra de forma eficiente. Quando o seu funcionamento não está de forma adequada, pode estar ocorrendo algum tipo de infecção, lesão ou doença, entretanto, em condições normais, todo trato urinário é estéril e diversos mecanismos contribuem para isso. A infecção do trato urinário, é caracterizada pela invasão e multiplicação de fungos ou bactérias nos órgãos do sistema urinário, podendo atingir os rins e/ou as vias urinárias e deve ser tratada o mais rápido possível para diminuir o risco de maiores complicações (Oliveira et al., 2018).

\subsection{Infecção do Trato Urinário}

A infecção do trato urinário (ITU) é a invasão, multiplicação e colonização por bactérias de parte do sistema urinário. É caracterizada por ser uma patologia frequente, atingindo um público de todas as idades, mas apresenta maior incidência entre os grupos de riscos como mulheres e grávidas, pacientes diabéticos, crianças, idosos e portadores de doença arterial coronária (Silva et al., 2020). Em relação a predominância ao sexo feminino, essa se dá principalmente devido à anatomia da uretra, relação sexual, episódios prévios de cistite, má higiene e gestação, apresentando uma prevalência maior em pacientes com baixa imunidade, obesas e com condições socioeconômicas baixas. A ITU é considerada grave quando se relacionar a fatores que facilitem a persistência da infecção como condições metabólicas, estenose, tumores, corpos estranhos e cateteres. Mas pode ser uma ITU simples quando se ater somente a bexiga e a uretra (Barreto et al., 2018; Lima, 2017).

A ITU é comumente frequente em mulheres gestantes, devido mudanças anatômicas e fisiológicas que ocorrem no seu organismo, em que cerca de 17 a $20 \%$ das gestantes brasileiras irão apresentar algum episódio de ITU, principalmente no segundo trimestre de gravidez, o que aumenta as chances de complicações materno-fecais. Esta é considerada a terceira intercorrência clínica mais frequente na gestação, ficando apenas atrás das infecções gastrointestinais e respiratórias (Menezes et al., 2020).

Os agentes patogênicos da infecção do trato urinários estão constantemente no ambiente hospitalar, e um dos setores que apresenta ambiente bastante favorável para a presença desses agentes é a Unidade de Terapia Intensiva (UTI), diante disso, alguns fatores contribuem para esse dado, como o longo período de internação, a diversidade e disseminação desses agentes provocadas pelo fluxo de pacientes submetidos a cirurgias, o uso de cateteres urinários e venosos, doença de base, ventilação mecânica, idade, estado imunológico e o uso de medicações imunossupressoras, fazendo com que os pacientes se tornem mais susceptíveis a desenvolver infecções (Mota et al., 2018).

Ademais esta patologia, clinicamente apresenta uma diversidade de sinais e sintomas e pode ser causada por uma variedade de micro-organismos. A ITU a princípio é classificada em superior/alta ou inferior/baixa, a primeira atinge os rins causando a pielonefrite, cuja infecção é mais frequente e complicada, visto que, em geral resulta da ascensão de microorganismos do trato urinário inferior, estando frequentemente associada a cálculos renais, tem como sintomas: febre e dor lateral, já a segunda, causa cistite, prostatite ou uretrite, associada ou não a forma assintomática, apresenta: disúria, poliúria, hematúria e sensibilidade supra púbica (Barreto et al., 2018; Lima, 2017; Brígido, 2020; Ferreira et al., 2017).

Os principais sintomas da ITU são micção dolorosa ou em queimação, dor na região lombar, micção frequente ou urgente e enurese noturna. O risco maior está na pielonefrite, visto que, ao se tornar crônica, pode comprometer a função dos 
rins, e em casos mais graves que levem a grandes complicações, provocar septicemia e morte (Lima, 2017). Ademais, a prevalência e a severidade da infecção, vão depender de alguns fatores como o quadro clínico de apresentação e histórico médico individual, e características demográficas (Brígido et al., 2020).

No que diz respeito a pacientes hospitalizados, a ITU é um grave problema de saúde pública, sendo a responsável pelo aumento da morbidade e mortalidade, além do período de internação, fazendo com que aumente bastante os gastos assistenciais, sendo a presença do cateter urinário o principal fator de risco (Silva et al., 2020).

Na ITU a contaminação do trato urinário pode se ocorrer de três formas. A primeira é através da via ascendente, a partir da flora fecal e uretral, a segunda forma é a hematogênica, em que a bactéria contamina o sangue e infecta de forma secundária o aparelho urinário, e por último a via linfática, que é uma forma duvidosa de disseminação da infecção urinária pelos vasos linfáticos, mas pode ter algum papel nas infecções crônicas (Caneppa, 2017).

A infecção do trato urinário, pode ser classificada também em complicada e não complicada. Determina-se a ITU não complicada, a que acomete mulheres jovens, não grávidas e que não apresentem anomalias funcionais ou estruturais no trato urinário. Já a ITU complicada possui alguns fatores que a caracterizam, como a diabetes, falência renal, gravidez, presença de sonda vesical de demora ou nefrostomia, obstrução do trato urinário, imunossupressão, história de ITU na infância, procedimento ou instrumentação cirúrgica recente no trato urinário e disfunções anatômicas ou funcionais (Haddad \& Fernandes, 2018).

Nessa perspectiva, a ITU é a segunda infecção bacteriana que ocorre majoritariamente em seres humanos, ficando atrás apenas da infecção respiratória. No nosso país, essa infecção é classificada como a mais frequente das infecções bacterianas, visto que, de 1.000 consultas clínicas, 80 são para ITU. É importante ressaltar que, a ocorrência do seu micro-organismo causador varia de região para região, assim, o perfil de suscetibilidade exige monitoramento para fornecer orientações e informações atualizadas de opções terapêuticas (Almada et al., 2017; Santos, M. J. A., et al., 2019). Um quadro infeccioso geralmente ocorre devido a bactérias ascendentes, oriundas de restos fecais ou da microbiota da pele vaginal ou perianal e da própria flora intestinal. Dentre os principais micro-organismos mais isolados em amostras de urinas, causadores de ITU, estão as bactérias gramnegativas, em geral o grupo das Enterobactérias, responsáveis por grande parcela das uretrites, cistites e pielonefrites, principalmente a Escherichia coli, Klebsiella pneumoniae, Proteus miriabili, Enterobacter spp e Pseudomonas aeruginosa também são conhecidas como importantes uropatógenos. Já bactérias gram-positivas são menos frequentes como agentes etiológicos da ITU, e as espécies de maior valor epidemiológico são Staphylococcus saprophyticus, Staphylococcus aureus, Streptococus agalactiae e Enterococcus faecalis. (Barreto et al., 2018; Salton \& Maciel, 2017; Menezes et al., 2020).

As enterobactérias caracterizam-se como uma das causas importantes de infecções humanas e também hospitalares. As hospitalares geralmente são causadas por bactérias multirresistentes, o que as torna cada vez mais importantes, devido à alta morbidade e mortalidade, atuando como agentes primários e oportunistas (Souza \& Souza, 2016).

A infecção caracteriza-se, primeiramente, pela invasão e multiplicação de bactérias localizadas no trato urinário, podendo ocorrer na uretra e encaminhar-se até os rins, ocasionando possivelmente bacteriúria. Ademais, esta patologia pode afetar apenas um local do corpo humano, como rins, bexiga, próstata ou uretra, de maneira que quando há a sintomatologia o quadro clínico é sugestivo para o diagnóstico, não obstante este só é confirmado por meio da realização do método denominado urocultura, fator imprescindível clinicamente (Salton \& Maciel, 2017).

\subsection{Urocultura e antibiograma}

A urocultura é caracterizada como o exame de maior eficácia no diagnóstico laboratorial de ITU. A infecção urinária corresponde ao crescimento de no mínimo, 100 mil unidades formadoras de colônia (UFC) por mililitro de urina colhida em jato médio e com todas as condições de assepsia (Almada et al., 2017). Esse exame é considerado o padrão-ouro para a confirmação quanto as infecções do trato geniturinário baixo ou alto (Souza \& Souza, 2016). Para sua realização, semeia-se a urina com alça 
calibrada estéril de $1 \mu \mathrm{L}$, em determinado meio de cultura correto para a produção de bactérias. A realização pode ser feita em ágar CLED (Cystine Lactose Electrolyte Deficient), visto que esse permite o crescimento de todos os micro-organismos potencialmente patogênicos que estão presentes na urina, e ágar MacConkey, que torna possível o crescimento seletivo de bacilos gram-negativos. Logo após 24 horas de incubação das placas na estufa bacteriológica em temperatura de $35^{\circ}$ a $37^{\circ} \mathrm{C}$, se a urina apresentar germes, pode-se identificar a formação de colônias de bactérias e qual o agente causador da infecção. Porém se o crescimento for precário ou inexistente, as placas serão reincubadas por mais 24 horas, fazendo a leitura no final de 48 horas. Com o diagnóstico positivo, o crescimento bacteriano corresponde a pelo menos 100.000 unidades formadoras de colônias por $\mathrm{ml}$ de urina $\left(10^{5} \mathrm{UFC} / \mathrm{ml}\right)$, e a presença de um número consideravelmente grande de bactérias na urina é chamada de bacteriúria (Lima, 2017).

Além da urocultura, é recomendável a realização do antibiograma, que também é conhecido como Teste de Sensibilidade a Antimicrobianos - TSA ou técnica de Kirby-Bauer, para amostras positivas. O teste é feito semeando as bactérias de forma homogênea com swab estéril em placas de ágar Müeller-Hinton, em que são colocados em seguida pequenos discos contendo antibióticos. Posteriormente, a placa é levada para a estufa por mais 24 horas e, logo após, observa-se se houve ou não crescimento bacteriano na região dos discos. Se tiver a formação de um halo de inibição do crescimento ao redor dos discos, é medido seu diâmetro em milímetros e interpretado como resistente ou sensível. Diante disso, esta técnica de disco-difusão, permite saber a resistência ou sensibilidade da bactéria frente aos principais antibióticos utilizados, caracterizando-se como uma ferramenta de suma importância para o monitoramento da evolução da resistência bacteriana, além disso, auxilia na aplicação de medidas de controle para evitar o aumento de bactérias multirresistentes e pode ser realizado para confirmar a susceptibilidade ao antimicrobiano selecionado com base em dados clínicos (Andrade, 2017).

No entanto, a grande incidência, os sintomas desagradáveis e a delonga na realização da urocultura e antibiograma, fazem com que normalmente a terapia seja iniciada antes mesmo que os resultados dos exames sejam conhecidos. Infelizmente, tanto a urocultura, quanto o antibiograma possuem um custo elevado e não são realizados pelos serviços básicos de saúde oferecidos para a população, que geralmente não tem condições financeiras para sustentar os exames na rede privada. Nesse caso, os médicos de pronto atendimento na maioria dos casos, fazem uso da terapia empírica, baseando-se apenas no quadro clínico do paciente, sem qualquer embasamento laboratorial, daí a importância do conhecimento dos principais agentes etiológicos envolvidos e qual seu perfil de resistência frente aos antibióticos. (Alves et al., 2016).

\subsection{Resistência a antimicrobianos}

O tratamento para as infecções bacterianas é realizado através de antibioticoterapia específica para cada espécie, seguindo a recomendação das diretrizes internacionais, devido a sua superioridade de melhora clínica em relação ao placebo. No entanto, a eficácia dos tratamentos vem sendo prejudicada nos últimos anos devido à mudança do perfil de suscetibilidade dos micro-organismos e a emergência de novos mecanismos de resistência a antimicrobianos (Venturieri et al., 2019).

A resistência bacteriana se dá por diversos mecanismos, sendo eles intrínsecos ou adquiridos. A resistência intrínseca acontece de forma natural, como parte de um processo de evolução bacteriana, enquanto a resistência adquirida realiza-se por meio da pressão seletiva exercida pelo uso indiscriminado de antimicrobianos, podendo levar a mutações genéticas, tendo origem genes de resistência que podem ser transferidos entre as espécies bacterianas (Mota et al., 2018). A resistência bacteriana é ocasionada por vários mecanismos, dentre eles, intrínsecos, que ocorrem de forma natural, como parte de um processo de evolução bacteriana, e adquiridos, que se realiza por meio da pressão seletiva exercida pelo uso indiscriminado de antimicrobianos, levando a mutação e recombinação de genes que podem ser transferidos entre as espécies bacterianas. Uma consequência dessa resistência é a falta de opções de antibióticos para serem utilizados em tratamentos para casos mais graves, criando a necessidade de cada vez mais antimicrobianos de última geração, mas o processo de descoberta de novos fármacos é 
mais lento quando comparado ao número de resistências bacterianas (Machado et al., 2019)

Em relação aos mecanismos de resistência, um dos que merecem maior destaque e são frequentes em gram-negativas ocorre através da produção de enzimas, como as betalactamases por exemplo. Codificadas por plasmídeos ou cromossomos, estas enzimas são capazes de hidrolisar o anel betalactâmico provocando a inativação de drogas betalactâmicas. E com relação as betalactamases, destacam-se as de espectro estendido, também chamadas ESBL (Extended-Spectrum BetaLactamase), que promovem resistência para penicilinas, cefalosporinas, monobactâmicos, carbapenêmicos, além de resistência a inibidores de betalactamases, como ácido clavulânico, sulbactam e tazobactam. Esta capacidade acontece principalmente em cepas de Klebsiella spp., E. coli, e em menor frequência com Pseudomonas spp. Ademais, cerca de 50\% dos isolados de K. pneumoniae são ESBL positivas, com uma maior frequência em ambiente hospitalar (Mota et al., 2018).

Entretanto, um dos principais problemas de resistência está relacionado a cepas de Acinetobacter spp., P. aeruginosa e bactérias da família Enterobacteriaceae que tem a capacidade de produzir betalactamases de espectro estendido (ESBL) e cepas de K. pneumoniae que produzem carbapenases. A existência dessas bactérias em processos infecciosos tem provocado um elevado índice de mortalidade, tornando-se um sério problema tanto no Brasil como em outros países (Mota et al., 2018).

Os antibióticos são classificados segundo seu mecanismo de ação, assim, os aminoglicosídeos, macrolídeos, cloranfenicol, tetraciclinas e estreptomicinas atuam inibindo a síntese proteica; as quinolonas e rifamicinas atuam interagindo com o processo da síntese de de DNA e RNA; enquanto os glicopeptídeos e os betalactâmicos agem na parede celular bacteriana e as sulfonamidas alteram o metabolismo bacteriano (Rocha \& Resende, 2017).

O Brasil adota preferencialmente, alguns esquemas de antibióticos para a terapia de ITU, sendo eles: sulfametoxazoltrimetoprim, as fluorquinolonas, os betalactâmicos, a amoxicilina e a nitrofurantoína. No entanto, a utilização empírica desses antimicrobianos não é aconselhável quando sua taxa de resistência, para certo micro-organismo for superior a 20\%. Todavia, o uso inadequado desses antibióticos pode levar a resistência bacteriana, visto que as bactérias possuem genes relacionados a resistência, que podem ser transferidos de uma para outra por meio de plasmídeos (Lima, 2017).

A ANVISA (Agência Nacional de Vigilância Sanitária) em virtude do grande aumento de bactérias resistentes a inúmeros antimicrobianos, determinou na RDC n 20/2011 que os antimicrobianos só poderiam ser dispensados mediante apresentação de prescrição médica, sob duas vias, em que uma ficará com o paciente carimbada pela farmácia como comprovante de atendimento e a outra permanecera no estabelecimento farmacêutico, visando com isso, reduzir a automedicação. Além dessa medida, a ANVISA também determinou a utilização da tarja vermelha nos rótulos e embalagens dos medicamentos antimicrobianos, contando a frase "Venda sob prescrição médica - Só pode ser vendido com retenção de receita", ademais, a resolução traz a lista de todos os antimicrobianos corretamente registrados pela ANVISA (Rocha \& Resende, 2017).

Diante do exposto, o presente estudo tem o objetivo de avaliar a prevalência das principais bactérias encontradas em uroculturas causadoras de ITU em pacientes ambulatoriais e atendidos em hospitais dos diferentes estados brasileiros, bem como o perfil de resistência e sensibilidade bacteriana a antimicrobianos, por meio da busca em um banco de dados atualizados, promovendo uma revisão do tema proposto.

\section{Metodologia}

\subsection{Delineamento do estudo}

Marcone \& Lakatos (2007), afirmam que o levantamento de dados por meio de fontes variadas é fundamental em qualquer pesquisa, seja ela de natureza documental ou não, correspondendo à fase em que se coletam informações prévias sobre o campo de interesse.

Consistiu-se de uma revisão integrativa de literatura, isto é, a análise de pesquisas relevantes que dão suporte para a tomada de decisão e a melhoria da prática clínica, fazendo com que seja possível a síntese do estado de conhecimento de 
determinado assunto, além de frisar lacunas do conhecimento que necessitam ser preenchidas com relação a novos estudos. Ademais, esse método de pesquisa permite a síntese de diversos estudos publicados de forma sistemática e ordenada, sendo possível tirar conclusões gerais relacionadas a determinada área particular de estudo (Barbalho et al., 2019).

\subsection{Fontes de informação}

Para realização desse estudo de revisão literária, foi feito uma busca de artigos recentes (até 7 anos da publicação) nos bancos de dados de periódicos eletrônicos Pubmed, Medline, Lilacs e Scielo, com disponibilidade de textos completos para a coleta de dados que contenham as principais bactérias encontradas em uroculturas de pacientes com Infecções do Trato Urinário (ITU) juntamente aos sua resistência frente aos mais diversos tipos de antibióticos.

\subsection{Critérios de busca}

Foi encontrada uma grande quantidade de artigos utilizando como palavras-chave os descritores: Infecção urinária, Infecção do Trato Urinário, Bactérias encontradas em pacientes com ITU, Resistência Bacteriana em Uroculturas e Uroculturas. A partir destes foram selecionadas as informações mais relevantes para a composição deste estudo retrospectivo, quantitativo, descritivo.

\subsection{Critérios de inclusão e exclusão}

Incluiu-se ensaios clínicos randomizados, artigos originais, revisões, consensos e trabalhos de conclusão de curso publicados entre os anos de 2014 a 2021 utilizando os idiomas português, inglês e espanhol, que tratassem sobre as principais bactérias encontradas em uroculturas e seu perfil de resistência frente aos antimicrobianos e com disponibilidade de textos completos. Tendo como critérios de exclusão, qualquer artigo que não trate de nenhum dos temas anteriormente citados, por exemplo, tinha artigo que abordava apenas o público gestantes, esses foram descartados, sendo assim selecionados aqueles em que prevaleciam as mesmas bactérias, além desses, os que tivessem sido publicados fora do tempo cronológico delimitado e os que não estavam acessíveis por completo. Assim, de um total 92 artigos através dos descritores em diferentes plataformas de pesquisa online, após filtragem dos temas abordados nos diferentes artigos, foram selecionados apenas os que estavam de acordo com os critérios de inclusão e exclusão para a realização do presente estudo.

\subsection{Seleção dos artigos}

Inicialmente, foi realizada uma triagem dos dados com o objetivo de selecionar os dados mais viáveis para o estudo. Para traçar o perfil de resistência foram observadas as três bactérias de maior incidência no estudo, tanto para ambulatoriais, quanto hospitalar e, a partir dessas bactérias, foram realizados os mapeamentos dos perfis de suscetibilidade por bactéria, depois disso fez-se uma análise dos principais artigos que continham antimicrobianos de mesma classificação, ou seja, os que mais se repetiam de acordo com as bactérias mais prevalentes.

\section{Resultados e Discussão}

\subsection{Prevalência de ITU de acordo com o gênero}

Para o desenvolvimento do estudo, fez-se uma análise em cerca de 92 artigos, dentre esses, 10 foram selecionados para a coleta de dados para construção do gráfico 1 e 2, e 5 artigos para a coleta de dados e construção da tabela 1 e gráfico 3, totalizando 4173 uroculturas positivas. Dentre essas uroculturas, 3385 (81\%) pertencem ao gênero feminino e 788 (19\%) pertencem ao gênero masculino, como observa-se no Gráfico 1 abaixo, em um perfil que englobou todas as idades. 
Gráfico 1. Representação da prevalência de Infecção do Trato Urinário de acordo com o gênero.

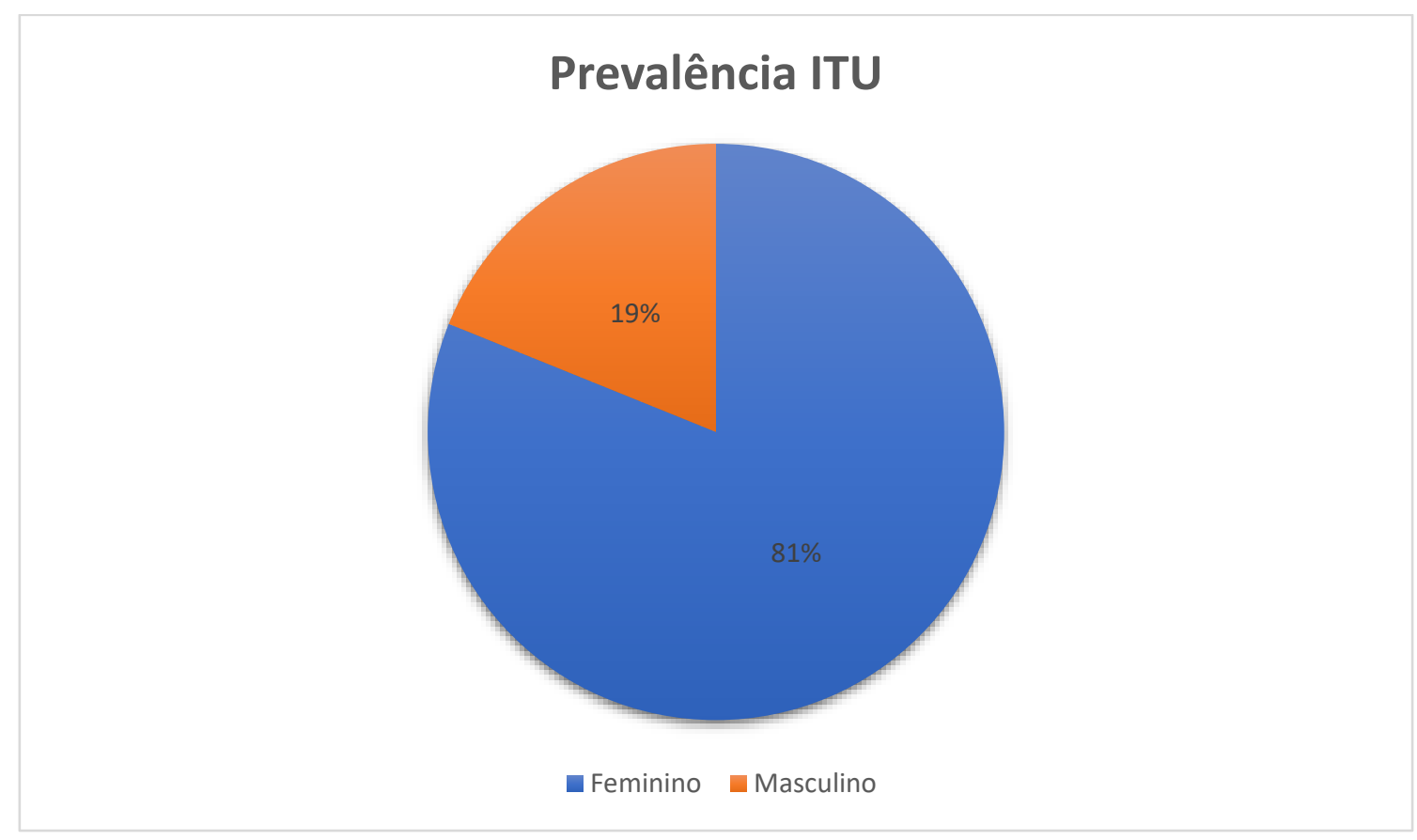

Fonte: Autores.

Esta maior susceptibilidade de ITU em mulheres quando comparada aos homens prevaleceu em toda a literatura analisada, e a maioria dos autores justificam esse dado devido a uretra da mulher ser de um tamanho bastante inferior em relação a do homem, e também pela proximidade que existe entre o ânus e a vagina, o que ocasiona uma grande colonização da vagina pela microbiota intestinal (Vinhal, 2018).

Além de todas estas características anatômicas, existem diversos outros fatores que contribuem para prevalência de ITU em mulheres, que são a gravidez, o ato sexual, infecções recorrentes, má higiene pessoal, o uso de calças apertadas por um longo período de tempo e diabetes. A utilização de preservativos com espermicidas, a menopausa e o período menstrual, podem afetar o pH e como consequência a flora vaginal, o que favorece o aparecimento de germes no trato urinário (Lima, 2017).

\subsection{Principais bactérias encontradas em uroculturas}

O sistema urinário em condições normais contém uma quantidade pequena de micróbios, mas frequentemente, sujeitase a infecções oportunistas que podem ocasionar uma série de problemas, e a maioria dessas infecções têm origem bacteriana (Tortora, 2017).

Assim, construiu-se o Gráfico 2 abaixo por meio de uma análise da base de dados pesquisados e, de acordo com isso, resultou-se na média de micro-organismos mais prevalentes encontrados na urocultura de pacientes. Paralelo a isso, condensouse as informações relevantes na pesquisa realizada, de maneira a observar os agentes causadores em maior frequência de ITU. 
Gráfico 2. Frequência de micro-organismos isolados em uroculturas.



Fonte: Autores.

A partir do que se observa no gráfico, as bactérias que prevalecem no achado de urocultura são a Escherichia coli com 66,97\% dos casos, Klebsiella pneumoniae, com 11,7\% dos casos e Proteus miriabilis com 4,67\% dos casos. Esses microorganismos são pertencentes à família Enterobacteriaceae, que são residentes do intestino humano e consideradas grandes causas de ITU, infecções hospitalares, sanguíneas, pneumonias e várias infecções intra-abdominais (Barreto et al., 2018). Deve ser ressaltado que são bactérias gram-negativas e apresentam uma probabilidade alta de desenvolvimento de mecanismos de resistência frente a antibioticoterapia. O grande predomínio de bactérias gram-negativas em ITU é devido elas serem oriundas da microbiota intestinal, podendo vir a ocasionar infecções, desde uma cistite até uma pielonefrite. Estas bactérias são multirresistentes, visto que sofrem modificações celulares, e são responsáveis por alguns tipos mais comuns de infecções de trato urinário, corrente sanguínea e pneumonia (Coutinho et al., 2019).

De acordo com o gráfico 2, observa-se a prevalência de bactérias gram-negativas com predominância para o agente mais isolado, Escherichia coli, isso porque a flora intestinal é abundante em enterobactérias e esta região fica próximo à uretra, a principal fonte de entrada para os patógenos urinários e onde frequentemente as infecções urinárias são iniciadas (Tortora, 2017). Além disso, a E. coli é constituída por fímbrias, que auxiliam a sua fixação na parede do trato urinário, fazendo com que dificulte o seu arraste pela urina (Lima, 2017). Vale lembrar que a E. coli é o micro-organismo mais frequentemente encontrado tanto em pacientes hospitalizados quanto em ambulatoriais (Alves et al., 2016). Esta bactéria pertence a flora intestinal normal, e sua presença indica contaminação fecal. Pelo fato da proximidade do canal vaginal com o ânus a infecção por essa bactéria se apresenta bastante frequente (Tortora, 2017).

O segundo patógeno mais frequente nos isolados de urocultura foi a Klebsiella pneumoniae (11,7\%), que é caracterizada como um patógeno oportunista, por causar infecções em pacientes imunocomprometidos, além de estar associada a pneumonias e infecções em outros órgãos. No ambiente hospitalar provoca infecções urinárias com altos graus de resistência a partir de diversos mecanismos de resistência, como a produção de cabepenemases e betalactamases (Souza \& Souza, 2016). 
A ITU é causada principalmente por meio da ascensão de enterobactérias na uretra. Assim, Proteus mirabilis também se apresentou como um dos uropatógenos mais encontrados em uroculturas, com 4,67\% dos casos, sendo prevalente em ambos os sexos, entretanto em pacientes masculinos e em crianças o P. mirabilis é um patógeno de importante causa, visto que essa bactéria frequentemente coloniza a região prepucial, de modo que é importante atentar para tal informação, visto que deve-se analisar cuidadosamente os esquemas antimicrobianos empíricos que são de amplo espectro no momento da prescrição, já que a sensibilidade antimicrobiana deste micro-organismo não coincide com o da E. coli, uma das mais prevalentes também encontradas (Alves et al., 2016).

Outra bactéria encontrada nas uroculturas, responsável por 4,32\% dos casos foi a Enterobacter spp., que pertence ao grupo de bactérias gram-negativas e são definidas como anaeróbias facultativas, vive comensalmente e podem infectar tanto os homens quanto os animais, tendo como seu local de maior proliferação, o intestino (Coutinho et al., 2019).

Observa-se também a prevalência de Pseudomonas sp., não tão prevalente quanto as duas primeiras, com apenas 2,29\% dos casos, mas apresenta-se como importante fator clínico, visto que também é Gram negativa com potencial de resistência a múltiplos antibióticos e geralmente, este micro-organismo não é integrante da microbiota normal de hospedeiros saudáveis, estando associada a ITU complicadas e de origem hospitalar (Barreto et al., 2018). Faz-se necessário salientar que na base de dados utilizados encontra-se ao menos alguns desses micro-organismos, sendo a E. coli a mais prevalentes no que se refere ao principal causador de ITU, de maneira que não depende da população investigada, dessa forma, avalia-se a disseminação ampla de tais bactérias.

Uma pequena porcentagem foi encontrada em Enterococus faecalis (2,54\%) e em Staphylococus aureus (2,42\%), representando os cocos gram-positivos, eles são caracterizados como os agentes etiológicos que acometem mulheres idosas e grávidas (Barreto et al., 2018), além de também possuir como alvo pacientes hospitalizados. A média de outros micro-organismos encontrados em uroculturas foi de $5,09 \%$.

\subsection{Perfil de resistência bacteriana na ITU frente aos antimicrobianos}

$\mathrm{O}$ antibiograma é caracterizado como o exame de maior importância à terapêutica do paciente, visto que possibilita a devida escolha do tratamento adequado e racional para aquele caso específico. O demasiado uso de antibióticos e sua utilização inapropriada fizeram com que micro-organismos se tornassem resistentes a diversos grupos de fármacos. Quando os antibacterianos não afetam a multiplicação bacteriana, tem-se o fenômeno da resistência que restringe a ação dos medicamentos disponíveis para o tratamento das infecções (Almada et al., 2017). E um fator de risco para o desenvolvimento dessa resistência bacteriana, é devido a demora na liberação de resultados de cultura e antibiograma, fazendo com que a prescrição empírica de antimicrobianos para este tipo de infeção seja bastante comum. Baseado nisso, estudos que demonstram resultado prévio da prevalência de agentes patogênicos mais comuns em determinada área geográfica, além do seu perfil de resistência frente aos antimicrobianos prescritos permitem o estabelecimento de um tratamento mais adequado e racional, e consequentemente, a redução do número de novas cepas resistentes (Brígido et al., 2020).

Diante disso, a Tabela 1 abaixo, foi construída baseada na análise da base de dados pesquisada, em que informa o perfil de resistência das principais bactérias encontradas em uroculturas de pacientes com ITU, frente a alguns antimicrobianos, após realização do antibiograma.

Por meio disso, pode-se observar informações relevantes, que auxiliariam no direcionamento do tratamento desses pacientes, que estão internados na maioria dos casos, promovendo maior eficácia da terapêutica, visto que apresenta quais os antibióticos que têm maior resistência e os que tem menor resistência, sensibilizam e eliminam a bactéria especifica para infecção naquele determinado paciente.

Para poder estabelecer uma terapia empírica eficiente, é de fundamental importância, levar em consideração não só os 
dados referentes ao agente causador de ITU, mas o sexo e a idade do paciente, em relação as propriedades farmacológicas antimicrobianas e histórico clínico do paciente, além disso, levar em consideração também, as diferenças de prevalência de agentes microbianos em cada região (Moraes et al., 2014).

Tabela 1. Perfil de resistência das principais bactérias encontradas em uroculturas de pacientes com ITU frente aos antimicrobianos.

\begin{tabular}{lccc}
\hline \multirow{2}{*}{ Antibiótico } & \multicolumn{2}{c}{ Espécies isoladas e resistência } \\
\cline { 2 - 4 } & E. coli (2395) & $\begin{array}{c}\text { Klebsiella } \\
\text { Pneumoniae } \\
(\mathbf{3 2 7})\end{array}$ & $\begin{array}{c}\text { Proteus Miriabilis } \\
(\mathbf{1 5 3})\end{array}$ \\
\cline { 2 - 4 } & $\mathbf{n}(\mathbf{\%})$ & $\mathbf{n}(\mathbf{\%})$ & $\mathbf{n}(\boldsymbol{\%})$ \\
\hline Ampicilina & $1325(55,32)$ & $220(67,27)$ & $63(41,17)$ \\
Sulfametoxasol+Trimetropima & $823(34,36)$ & $110(33,63)$ & $75(49,01)$ \\
Gentamicina & $656(27,39)$ & $111(33,94)$ & $24(15,68)$ \\
Cefalotina & $563(23,50)$ & $54(16,51)$ & $18(11,76)$ \\
Norfloxacino & $558(23,29)$ & $118(36,08)$ & $29(18,95)$ \\
Ciprofloxacino & $533(22,25)$ & $80(24,46)$ & $33(21,56)$ \\
Amoxilina+Clavulanato & $459(19,16)$ & $57(17,43)$ & $39(25,49)$ \\
Ácido Nalidíxico & $402(16,78)$ & $31(9,48)$ & $31(20,26)$ \\
Amicacina & $274(11,44)$ & $16(4,89)$ & $9(5,88)$ \\
Cefuroxima & $258(10,77)$ & $48(14,17)$ & $30(19,69)$ \\
Nitrofurantoína & $245(10,22)$ & $149(45,56)$ & $108(70,58)$ \\
Ceftriaxona & $231(9,64)$ & $86(26,29)$ & $28(18,30)$ \\
\hline
\end{tabular}

Fonte: Autores.

Observou-se anteriormente um padrão nos resultados onde houve uma prevalência de $E$. coli nos pacientes com Infecção do Trato Urinário (ITU) como se observou no gráfico 2, em seguida tivemos a prevalência de Klebsiella pneumoniae, e Proteus mirabilis. Em virtude desses resultados, a realização do antibiograma para análise da resistência a E.coli, (bactéria mais prevalente em ITU), frente os antibióticos, faz-se demasiadamente importante, seguido pela Klebsiella pneumoniae, e Proteus mirabilis como mostra a tabela 1 e no Gráfico 3 abaixo. 
Gráfico 3. Frequência relativa da resistência bacteriana aos principais agentes antimicrobianos utilizados no tratamento de infecção do trato urinário no estudo.



Fonte: Autores.

Durante análise dos artigos, percebeu-se que todos apontam que a princípio deve ser realizado buscas de dados epidemiológicos da região em questão, para assim familiarizar-se sobre os principais patógenos existentes e seu perfil de suscetibilidade.

Na Tabela e Gráfico acima, observa-se o perfil de resistência das principais bactérias encontradas em pacientes com ITU frente a antibióticos, em que a E. coli, mostrou-se mais resistente na maioria dos casos à ampicilina (55,32\%), sulfametoxazol+trimetroprim $(34,36 \%)$ e a gentamicina $(27,39 \%)$, dentre esses, a ampicilina foi a que se mostrou menos eficaz ao tratamento, ou seja, das 2395 E. coli isoladas em urocultura, 1325 apresentaram resistência frente a esse antibiótico, apesar de ser o fármaco de escolha para ser administrado em pacientes grávidas, foi o que obteve maior resistência frente a essa bactéria.

A segunda espécie mais isolada, Klebsiella pneumoniae, das 327 isoladas, 220 (67,27\%) apresentaram resistência a ampicilina, seguido por nitrofurantoína (45,56\%) e posteriormente norfloxacino (36,08\%). A espécie Proteus miriabilis apresentou resistência principalmente a nitrofurantoína, visto que das 153 espécies isoladas, 108 apresentaram resistência a esse antibiótico, um total de 70,58\% de resistência, seguido de sulfametoxasol+trimetropim (49,01\%), ampicilina (41,17\%) e amoxilina+clavulanato $(25,49 \%)$. Ao final da análise, pode-se concluir que amplicilina e sulfametoxasol+trimetropim foram os dois esquemas terapêuticos que apresentaram maior percentual de resistência, para as três espécies de bactérias analisadas e a nitrofurantoína se mostrou bastante resistente em relação as espécies Klebsiella pneumoniae e Proteus miriabilis, não sendo recomendáveis para o tratamento de ITU. Os antimicrobianos que apresentaram menos resistência foram amicacina, cefuroxima e ceftriaxona nas três espécies isoladas como se observa no gráfico 3 acima.

Os mecanismos de resistência bacteriana podem ser definidos de três formas principais, são elas: a característica específica de tais bactérias em relação ao desempenho de determinado antibiótico, capaz de resistir a sua ação; ou ser adquirida 
por mutação que podem decorrer durante a replicação celular, ou através de agentes mutagênicos, e além dessas, também adquirida pela obtenção do material genético "herdada" de outros micro-organismos que tinham genes de resistência por meio de transmissão gênica (Coutinho et al., 2019).

$\mathrm{O}$ antimicrobiano que apresentou maior resistência dentre os analisados no geral, foi a ampicilina, que pertence a classe dos $\beta$-lactâmicos e, apesar da sua grande porcentagem de resistência, é um medicamento considerado terapia de primeira linha para bactérias sensíveis em gestantes, visto que ainda não há relatos de efeitos nocivos fetais, o que acontece com a maioria dos antimicrobianos que tratam a ITU (Barreto et al., 2018). A ampicilina é bastante resistente e um dos motivos disso é por ela pertencer ao grupo das penicilinas, que são antibióticos de primeira geração e não são mais tão eficientes contra a maioria das bactérias (Lima, 2017).

A alta resistência microbiana da associação sulfametoxasol+trimetropim, é justificada por se tratar de um dos antimicrobianos mais antigos e também mais utilizados na prática clínica, principalmente para se tratar ITU, e um possível uso indiscriminado e aleatório como a automedicação, assim esta droga não é recomendada como primeira escolha para se iniciar uma terapia empírica para este tipo de infecção (Freitas, 2015). Além disso, alguns mecanismos justificam essa resistência: bombas de efluxo, desregulação na expressão dos genes que codificam a enzima-alvo, desenvolvimento de barreiras na permeabilidade da membrana e alterações nos locais de ligação às enzimas (Lima, 2017).

Outro antibiótico que apresentou um alto perfil de resistência foi a nitrofurantoína, mesmo esta sendo uma das escolhas de primeira linha para o tratamento de cistites não complicadas, por causa dos seus mínimos efeitos colaterais, sua disponibilidade e eficácia. Em relação a E. coli, este antimicrobiano apresentou baixa incidência de resistência, com isso, a nitrofurantoína pode ser utilizada na terapia de ITUs não complicadas, observando-se o agente etiológico em questão e seu perfil de sensibilidade. Já em relação a Klebsiella pneumoniae e Proteus miriabilis, estes apresentaram uma considerável resistência a nitrofurantoína, assim o tratamento com esse antimicrobiano não é recomendável e se for, deve ser feito com cautela (Cornelli, 2018).

Em relação aos antimicrobianos de menor resistência, a amicacina que foi considerada de boa sensibilidade frente às bactérias analisadas, é classificada como um aminoglicosídio, e estes são eficazes contra bactérias gram-negativas e grampositivas, e frequentemente são utilizados no tratamento de ITU combatendo a infecção. Porém, esta classe tem uma perfusão dificultada no rim de pacientes com insuficiência renal, sendo assim, não indicada devido a consequente toxicidade e por estarem disponíveis apenas na forma injetável. O uso de aminoglicosídeos na terapia empírica, somente é indicada em caso de suspeita de patógenos resistentes ou em pacientes com intolerância a outros agentes eficazes; deve ser reavaliada a continuidade do tratamento posteriormente os resultados de cultura de urina. Já a ceftriaxona, também um antimicrobiano com pouca resistência frente as bactérias analisadas, é da classe das cefalosporina de terceira geração, frequentemente usada para micro-organismos multirresistentes (Barreto et al., 2018).

As cefalosporinas em geral, incluindo ceftrtiaxona e cefuroxima, foram as drogas que em grande parte da literatura atingiram taxas recomendadas para terapia empírica, e os autores afirmam que essa preferência se dá pelo fato da boa eficácia dessas drogas tanto em relação as bactérias gram-negativas quanto as gram-positivas. Todavia, para a escolha da terapia com o antibiótico adequado, o tratamento deve ser direcionado contra o patógeno causador da doença, e se não houver esse dado, para o patógeno mais provável, de forma que o amplo espectro das cefalosporinas não quer dizer que sempre serão drogas de primeira escolha médica, visto que as diferentes gerações possuem diversas utilidades (Vinhal, 2018).

Segundo Bitencourt \& Pavanelli (2014), em estudo realizado no Rio de Janeiro, revelou alta resistência de E. coli a sulfametoxazol-trimetropim e ampicilina e maior sensibilidade a nitrofurantoína, ácido nalidíxico, aminoglicosídeos, quinolonas e cefalosporinas de segunda e terceira geração; basicamente todos os estudos analisados demonstraram esses resultados. O aumento frequente de bactérias que são resistentes a diversos fármacos antimicrobianos significa um enorme desafio no 
tratamento dessas infecções, portanto com a coleta desses dados é possível conhecer as susceptibilidades dos pacientes, nortear o tratamento e até mesmo prevenir ou evitar maiores agravos.

\section{Conclusão}

Os dados coletados através de diversas bases de dados atualizadas, promovem o conhecimento a cerca dessa infecção, que consiste em uma das mais prevalentes principalmente no âmbito hospitalar, que é a Infecção do Trato Urinário, demonstrando ser a E. coli a bactéria mais frequente nesse tipo de infecção, seguido pela Klebsiella pneumoniae, Proteus mirabilis, Enterobacter spp., além disso, foi possível avaliar o perfil de resistência e sensibilidade desses agentes microbianos a antibióticos, chegando à conclusão que amplicilina e sulfametoxasol+trimetropim foram os dois esquemas terapêuticos que apresentaram maior percentual de resistência e amicacina, cefuroxima e ceftriaxona, os antimicrobianos que apresentaram menor resistência nas três espécies isoladas, criando assim um esquema terapêutico que auxiliará os profissionais da saúde durante o tratamento dos pacientes com ITU. Desta forma, uma investigação em cada centro de saúde traçando o perfil de prevalência e susceptibilidade aos antibióticos faz-se necessário, em virtude das características e especificidades de cada serviço.

\section{Referências}

Almada, D. V., Gomes, H. B. S., Sousa, J. B., Nunes, M. A. S., Firmo, W. C. A., (2017). Antimicrobial resistance profile in patients served in a private laboratory in the municipality of Santa Inês-MA. Revista Uningá review. 30(3), 10-14.

Alves, D. M. S., Edelweiss, M. K., Botelho, L. J. (2016). Community urinary tract infections: prevalence and antimicrobial susceptibility in Florianópolis. Revista brasileira de medicina de família e comunidade. 11(38), 1-12.

Andrade, R. S. (2017). Proposta de seleção de fármacos aplicados ao teste de sensibilidade aos antimicrobianos para gestantes com infecção do trato urinário em âmbito nacional (Dissertação de mestrado). Fundação Oswaldo Cruz - Instituto Nacional de Infectologia Evandro Chagas, Rio de Janeiro, RJ, Brasil.

Barbalho, A. M. D. S., Andrade Júnior, F. P., Souza, E. K. M., Lima, I. O., Farias, A. D., Souza, J. B. P. (2019). Main antibacterials used in urinary tract infections and their possible risks during management: a review. Jornal of Medicine and Health Promotion. 4(4), 1267-1279.

Barreto, I. F., Ito, C. A. S., Bittencourt, J. I. M., Bail, M. (2018). Perfil de sensibilidade de bactérias isoladas em uroculturas de pacientes atendidos em um hospital localizado no estado do Paraná. Cadernos da Escola de Saúde, 17(2), 52-60.

Bitencourt, J. S. \& Pavanelli, M. F. (2014). Infecção urinária em pacientes da saúde pública de Campo Mourão-PR, Brasil: prevalência bacteriana e perfil de sensibilidade. Jornal brasileiro de patologia e medicina laboratorial. 50(5), 346-351.

Brígido, H. P. C., Araújo, A. C. M., Rios, M. M., Boettger, B. C., Prado, L. P., et al. (2020). Resistance profile of urinary infection agents in children admitted to a pediatric hospital in Belém do Pará. Brazilian Jornal of health Review. 3(4), 9808-9818.

Caneppa, A. A. (2017). Perfil de sensibilidade de microorganismos patógenos do trato urinário a antimicrobianos de uso clínico. (Trabalho de conclusão de curso). Academia de ciências e tecnologia, São José do Rio Preto, SP, Brasil.

Cornelli, I. (2018). Prevalência e perfil de sensibilidade aos antimicrobianos de bactérias isoladas de pacientes com infecção do trato urinário (ITU) atendidos no hospital universitário/UFSC. (Trabalho de conclusão de curso). Universidade Federal de Santa Catarina, Florianópolis, Brasil.

Corrêa, A. P. Ambrózio, C. L. Reis, R. (2018). Infecção do trato urinário em gestantes atendidas pelo sus na cidade de Bagé-RS. Revista congrega-mostra de trabalhos de conclusão de curso-ISSN. 47(2), 513-527.

Coutinho, E. R. S., Costa, A. K. A. N., Batista, P. F. S., Santos, A. N. (2019). Urinary tract infections: etiology and profile of antimicrobial sensitivity in nonhospitalized patients. Revista UNINGÁ. 56(3), 68-79.

Ferreira, V. M., Rossiter, L. N. V., Aragão, N. F. F., Pinto, O. A., et al. (2017). Community-acquired urinary tract infections in Divinópolis, Brazil: assesment of bacterial resistance profile and clinical management. Revista brasileira de medicina de família e comunidade. 12(39), 1-13.

Freitas, A. G. (2015). Perfil de resistência bacteriana em uroculturas no estado de Roraima no período de 2010-2015 (Dissertação de mertrado). Universidade Federal de Roraima, Boa Vista, RR, Brasil.

Haddad, J. M., \& Fernandes, D. A. O. (2018). Infecção do trato urinário. Femina. 47(4), 241-4.

Lima, A. D. P. (2017). Perfil de infecções bacterianas do trato urinário e resistência aos antibióticos (Trabalho de conclusão de curso). Universidade Federal de Uberlandia, Uberlândia, Brasil.

Machado, A. D., Naumann, D. C., Ferrazza, M. H. S. H., Tenfen, A., Silva, B. Y. G., Weber, K. (2019). Prevalence of urinary infection in a clinical analysis laboratory of Jaraguá do Sul city, SC, in the year 2017. Revista Brasileira de Análises Clínicas - RBAC. 51(3), 213-8.

Marconi, M. A. \& Lakatos, E. M. (2007). Fundamentos da Metodologia Científica, 6. ed., São Paulo: Atlas. 
Research, Society and Development, v. 10, n. 7, e5310716161, 2021

(CC BY 4.0) | ISSN 2525-3409 | DOI: http://dx.doi.org/10.33448/rsd-v10i7.16161

Menezes, F. M. C., Guimarães, B. M. A., Neto, A. G. S., Alves, L. L., Pinheiro, M. S. (2020). Urinary tract infection in pregnant women: assessing uropatogen susceptibility to antimicrobials in positive urocultures. Brazilian Jornal of health Review. 3(6), 17353-17364.

Moraes, D., Braoios, A., Alves, J. L. B., Costa, R. M. (2014). Prevalence of uropathogens and antimicrobial susceptibility profile in outpatient from Jataí-GO. Jornal brasileiro de patologia e medicina laboratorial. 50(3), 1676-2444.

Mota, F. S., Oliveira, H. A., Souto, R. C. F. (2018). Profile and prevalence of antimicrobial resistance of negative-Gram bacteria isolated from intensive care patients. Revista Brasileira de Análises Clínicas - RBAC. 50(3), 270-7.

Oliveira, S. M. \& Santos, L. L. G. (2018). Infecção do trato urinário: estudo epidemiológico em prontuários laboratoriais. Jornal Health NPEPS. 3(1), 198-210.

Rocha, T. B., \& Resende, F. A. (2017). Perfil de resistência da bactéria Escherichia coli a antibióticos em infecções do trato urinário em um laboratório de Curvelo/MG. Revista Brasileira de Ciências da Vida. 5(5), 1-14.

Salton, G., \& Maciel, M. J., (2017). Prevalência e perfil de resistência de bactérias isoladas em uroculturas de pacientes de uma cidade do interior do Rio Grande do Sul. Ciência \& Saúde. 10(4), 194-199.

Santos, A. M., Silveira, H. R. M., Lima, T. V. S., Pontes, I. E. A., (2020). Occurrence of urinary incontinence in practitioners of high impact sports: an integrative literature review. Temas em saúde. 20(2), 286-314.

Santos, F. A., Agra, A. S., Sena, J. T., Pereira, H. S., Silva, P. M. F. (2019). Prevalência de infecções urinárias de idosos e o perfil de resistência aos antimicrobianos. Anais VI Congresso Internacional de Envelhecimento Humano.

Santos, M. J. A., Porcy, C., Menezes, R. A. O. (2019). Etiologia e perfil de resistência bacteriana em uroculturas de pacientes atendidos em um hospital público de Macapá-Amapá, Brasil. Um estudo transversal. Revista diagnóstico e tratamento. 24(4), 135-42.

Silva, W. B, Sobral, N. O. B., Evangelista, D. R., Marson, P. G. (2020). Urinary tract infection: etiological and sensitivity profile to antimicrobials of urocultures of ambulatory patients and hospitalized in the city of Palmas-TO. Revista Cereus. 12(4), 13-24.

Souza, A. M., \& Souza, M. A. S. (2016). Enterobactérias Produtoras de Betalactamases de Espectro Estendido (ESBL) em isolados de uroculturas. Centro Universitário Tiradentes - UNIT, Maceió, AL, Brasil.

Tortora, G. J., Funke, B. R., Case, C. L. (2017). Microbiologia. Porto Alegre: Artmed.

Ventuvieri, V. R., Masukawa, I. I., Neves, F. S. (2019). Suscetibilidade a antimicrobianos de bactérias isoladas de culturas de urina provenientes do hospital universitário da Universidade Federal de Santa Catarina. Arquivos Catarinenses de Medicina. 48(1), $155-172$.

Vinhal, R. G. (2018). Perfil de resistência a antimicrobianos de pacientes com infecções do trato urinário atendidos em um laboratório de análises clínicas localizado no município de Luz - MG (Trabalho de conclusão de curso). Faculdade de filosofia, ciências e letras do Alto do São Francisco, Luz, MG, Brasil. 